\title{
Reação do tecido conjuntivo subcutâneo de ratos ao implante de Hipoglós $\mathbb{R}$
}

\author{
Reaction of the subcutaneous connective tissue of rats for the implant of Hipoglós ${ }^{\circledR}$ \\ Reacción del tejido conjuntivo subcutáneo de ratones al implante de Hipoglós ${ }^{\circledR}$ \\ Wilson Roberto POI $^{1}$ \\ Thaís da Silveira RODRIGUES CANASSA ${ }^{2}$ \\ Sônia Regina PANZARINI ${ }^{1}$ \\ Maria del Pilar RODRIGUEZ-SÁNCHEZ ${ }^{3}$ \\ Idelmo Rangel GARCIA JÚNIOR ${ }^{1}$
}

\author{
${ }^{1}$ Departamento de Odontologia e Clínica Integrada, Universidade Estadual Paulista (UNESP), \\ Faculdade de Odontologia, Araçatuba - 16015-050 Araçatuba - SP, Brasil \\ ${ }^{2}$ Universidade Paulista, UNIP, Campus Flamboyant, 74845-090 Goiânia-GO, Brasil \\ ${ }^{3}$ Programa de Odontología de Montería, UNISINU-Univ. Del Sinú - Colombia
}

\section{Resumo}

Introdução: a mucosa bucal é susceptível a lesões de origem externa ou interna, causados por diferentes agentes físicos, químicos e biológicos. Vários são os medicamentos testados para o tratamento das lesões da mucosa bucal. Objetivo: o propósito deste trabalho foi avaliar, microscopicamente em ratos, a reação do tecido conjuntivo subcutâneo ao implante de Hipoglós®. Material e Método: foram realizadas, no dorso de 15 animais incisões medindo $1 \mathrm{~cm}$ cada, com distância entre elas de $3 \mathrm{~cm}$. A partir daí, dois grupos experimentais foram constituídos: Grupo I - Controle (tubo de polietileno vazio); Grupo II - Hipoglós® (tubo de polietileno contendo Hipoglós®), considerando os períodos de 7, 15 e 21 dias, com cinco animais em cada um. Resultados: na análise histológica, o Grupo II (Hipoglós®) mostrou ainda células inflamatórias aos 21 dias, apesar de estatisticamente esse grupo ter apresentado melhores resultados quando comparado ao grupo I (Controle). Conclusão: em razão dos seus componentes e da semelhança de resposta inflamatória com o grupo controle, a pomada Hipoglós@ mostrou-se biocompatível em tecido conjuntivo subcutâneo de ratos e abre a perspectiva para a realização de outras pesquisas. Descritores: Vitamina A; Vitamina D; Óxido de Zinco; Tecido Conjuntivo.

\begin{abstract}
Introduction: the oral mucosa is susceptive to lesions due to external or internal origin, caused by physical, chemical or biological agents; different drugs have been tested to treat the oral mucosa lesions. Objective: the purpose of this study was to evaluate microscopically in rats, the reaction of the subcutaneous connective tissue to implant Hipoglós®. Material and Methods: it was performed on the back of the 15 animals incisions measuring $1 \mathrm{~cm}$ each, with a distance between them of $3 \mathrm{~cm}$. From there, two groups were formed: Group I - control (empty polyethylene pipe); Group II - Hipoglós® (polyethylene tube containing Hipoglós ${ }^{\circledR}$ ), considering the periods of 7, 15 and 21 days, five animals in each. Results: in the histological analysis, the Group II (Hipoglós ${ }^{\text {) }}$ also showed inflammatory cells at 21 days, although statistically this group presented better results when compared to group I (control). Conclusion: the components of the Hipoglós ${ }^{\circledR}$ showed similar inflammatory response to the control group, it proved to be biocompatible in subcutaneous connective tissue of rats and opens the possibility to carry out further research. Descriptors: Vitamin A; Vitamin D; Zinc Oxide; Connective Tissue.
\end{abstract}

\section{Resumen}

Introducción: la mucosa bucal es susceptible a lesiones de origen externa o interna, causados por diferentes agentes físicos, químicos y biológicos. Varios medicamentos han sido estudiados para el tratamiento de lesiones en la mucosa bucal. Objetivo: el propósito de este trabajo fue evaluar, microscópicamente la reacción del tejido subcutáneo el implante de Hipoglós ${ }^{\circledR}$. Material y Método: fueron realizadas 2 incisiones de 1centimetro cada una, a una distancia de 3 centimetros entre ellas, en el dorso de 15 animales. Los animales fueron divididos en dos grupos experimentales: Grupo I - Control (tubo de polietileno vacío); Grupo II - Hipoglós® (tubo de polietileno con Hipoglós®), considerando los períodos de 7, 15 e 21 días, con cinco animales en cada uno. Resultados: en el análisis histológica, el Grupo II (Hipoglós) mostro células inflamatorias a los 21 días, no obstante este grupo presento mejores resultados estadísticamente, al ser comparado con el grupo I (Controle). Conclusión: la respuesta inflamatoria obtenida en este estudio, con relación al Hipoglós $®$ fue similar al del grupo control, lo que indica la biocompatibilidad de esta pomada con relación al tejido conjuntivo subcutáneo en ratones y abre la perspectiva para la realización de otras investigaciones.

Descriptores: Vitamina A, Vitamina D, Óxido de Zinc, Tejido Conectivo.

\section{INTRODUÇÃO}

A mucosa bucal, não raro, é susceptível a vários traumas de origem externa ou interna, causados por diferentes agentes físicos, químicos e biológicos ${ }^{1,2}$. Como resultado dessa agressão instala-se uma reação inflamatória, desencadeando os sinais e sintomas decorrentes desse processo tais como: calor, rubor, tumor, dor e, muitas vezes, perda da função ${ }^{2}$.

Vários são os medicamentos utilizados para o tratamento das lesões da mucosa bucal. No que se refere à via de administração, opta-se, quando possível, pelos medicamentos tópicos objetivando prevenir não só efeitos colaterais, como também possíveis reações adversas ${ }^{2,3}$.

Dessa forma, a pomada Hipoglós $\AA$, um dos medicamentos tópicos mais tradicionais no país, apresentando em sua formulação agente ativos como as vitaminas A (retinol) e D (colecalciferol), além do óxido de zinco, torna-se uma opção possível de utilização na odontologia pelas características farmacológicas das substâncias que a constituem.

A vitamina A, também conhecida pela designação de retinol, é um álcool primário, polietilênico e lipossolúvel, apresentando grande capacidade reativa ${ }^{4}$. O termo retinóide 
se refere ao retinol ou aos seus derivados de ocorrência natural e análogos sintéticos, que não apresentam necessariamente atividade semelhante à do retinol. A vitamina A desempenha papel essencial na visão, crescimento, desenvolvimento do osso, desenvolvimento e manutenção do tecido epitelial, processo imunológico e reprodução ${ }^{4}$.

A vitamina $\mathrm{D}$, proveniente da síntese em animais, denominada colecalciferol ou vitamina $\mathrm{D}_{3}{ }^{5}$, tem papel essencial na homeostase. Classicamente, ela é necessária para a absorção do cálcio e do fósforo no intestino grosso, para a sua mobilização a partir dos ossos e para a sua reabsorção nos rins. Através destas três funções, a vitamina $\mathrm{D}$ tem um papel importante em assegurar o funcionamento correto dos músculos, nervos, coagulação do sangue, crescimento celular e utilização de energia. Tem sido proposto que a vitamina $\mathrm{D}$ é também importante para a secreção de insulina e prolactina, resposta imunitária e ao estresse, síntese da melanina e para a diferenciação das células da pele e do sangue ${ }^{5}$.

O zinco participa de reações na síntese ou degradação de carboidratos, lipídeos, proteínas e ácidos nucléicos. Também está envolvido nos processos de transporte, função imune e expressão da informação genética ${ }^{6}$.

Uma vez que os três constituintes da pomada têm ação sobre o sistema imunológico, parece razoável a pesquisa da pomada Hipoglós® em situações que desencadeiam reações inflamatórias.

O propósito deste trabalho é avaliar microscopicamente em ratos a reação do tecido conjuntivo subcutâneo ao implante de Hipoglós®.

\section{MATERIAL E MÉTODO}

Após aprovação do projeto de pesquisa junto à Comissão de Ética no Uso de Animais (CEUA) da Faculdade de Odontologia de Araçatuba (UNESP) foram utilizados 15 ratos (Rattus Norvegicus Albinus, Wistar) machos, com idade variando entre 70 a 90 dias, pesando aproximadamente 250 a $300 \mathrm{~g}$. Antes e durante a fase experimental os animais receberam ração sólida (Ração Ativada Produtor - Anderson \& Clayton S.A.). Durante todo o período experimental todos os animais receberam água à vontade.

Os animais foram anestesiados com Cloridrato de Quetamina (Vetaset - Fort Dodge) e Xilazina (Coopazine Coopers Brasil Ltda.) mediante injeção intramuscular, na dosagem de 0,2 e $0,1 \mathrm{ml}$ para cada 250 gramas de peso corpóreo, respectivamente. Após tricotomia e antissepsia da área cirúrgica com Dermoiodine (Gessy Lever Indústria Farmacêutica Ltda.), foram realizadas no dorso dos animais duas incisões com lâmina 15 , medindo $1 \mathrm{~cm}$ cada, com distância entre elas de $3 \mathrm{~cm}$, para evitar interações entre os grupos. A primeira delas foi feita na região anterior e a segunda na região posterior do dorso. Em seguida, o tecido foi divulsionado com tesoura romba até uma profundidade de $15 \mathrm{~mm}$.

A partir daí, dois grupos experimentais foram constituídos considerando os períodos de 7, 15 e 21 dias, com cinco animais em cada um. Os seguintes grupos foram avaliados: Grupo I - Controle (tubo de polietileno vazio); Grupo II - Hipoglós ${ }^{\circledR}$ (Retinol, colecalciferol e óxido de zinco, Procter \& Gamble, São Paulo, SP, Brasil).

Os tubos de polietileno (Tubo de P.V.C. atóxico siliconizado, Embaramed Ind. Com. Ltda., São Paulo, SP, Brasil), foram implantados nos espaços criados pelas divulsões. Após implantação, as bordas das feridas foram unidas por meio de sutura com fio de seda 4-0 (Ethicon).

Decorridos 7, 15 e 21 dias, a eutanásia de cinco animais de cada grupo, considerando os períodos, foi feita por injeção excessiva de anestésico.

Os implantes inseridos foram removidos em blocos com adesão de tecido conjuntivo. As peças obtidas foram fixadas em solução de formalina a $10 \%$ por duas semanas. A seguir, foram incluídas em parafina para possibilitar os cortes semi-seriados. Os cortes obtidos com uma espessura de seis micrometros foram corados pela hematoxilina e eosina (HE) para análise histomorfológica e histomorfométrica.

Os cortes histológicos foram analisados e a ocorrência dos fenômenos foi retratada a partir da "luz" do tubo de polietileno. Para a análise dos cortes histológicos, foi utilizado microscópio óptico binocular Jenamed 2 (CarlZeiss) ${ }^{7}$.

As avaliações quantitativas das células inflamatórias (linfócitos, plasmócitos, polimorfonucleares neutrófilos), macrófagos e células gigantes foram realizadas em 10 áreas separadas, de cortes com magnificação de $400 \mathrm{X}^{8}$. O valor médio de cada grupo foi obtido pela soma das células computadas nessas 10 áreas diferentes.

O total do valor médio obtido para cada grupo foi determinado por 5 animais de cada período. Os espécimes avaliados e submetidos à escores de 0 a 3: $0=$ nenhuma ou poucas células e sem reação; $1=$ menos que 25 células e reação discreta; 2 = entre 25 e 125 células e reação moderada; $3=125$ e mais que células e reação severa ${ }^{9}$.

O teste de Kolmogorov-Smirnov foi realizado para verificação da normalidade da distribuição dos dados ( $>0,05)$. A comparação da quantidade de células observadas para cada grupo (controle e hipoglós) nos diferentes períodos de tempo avaliados $(7,15$ e 21 dias) foi verificada por meio do teste one-way ANOVA, seguido pelo pós-teste de Tukey. $\mathrm{O}$ teste $\mathrm{t}$ de Student para amostras dependentes foi realizado para comparar a quantidade de células observadas no grupo controle e hipoglós para cada período de tempo analisado. Para o tratamento estatístico dos dados foi utilizado o pacote computacional SPSS for Windows (versão 15.0), adotando-se um nível de significância de 5\%.

\section{RESULTADOS}

\section{ANÁLISE QUALITATIVA}

Os resultados histomorfológicos obtidos são descritos em função dos períodos pós-operatórios nos diferentes grupos experimentais:

\section{○ 7 Dias}

$>$ Grupo I (Controle) - Próximo à abertura do tubo evidencia-se a presença de tecido conjuntivo exibindo moderado número de fibroblastos (Figura 1A). Notam-se, ainda, alguns linfócitos ao lado de vasos sanguíneos. Evidencia-se também pequeno número de vasos sanguíneos. Nas áreas situadas mais distantes da abertura do tubo, o tecido conjuntivo apresenta praticamente as mesmas características acima descritas.

$>$ Grupo II (Hipoglós $\left.{ }^{\circledR}\right)$ - Em alguns espécimes observa-se nas proximidades da abertura do tubo elevado número de linfócitos e macrófagos (Figura 1D ). Evidenciamse ainda alguns polimorfonucleares neutrófilos. Nas áreas mais afastadas da abertura do tubo, podem ser evidenciados alguns fibroblastos. Em outros espécimes, a presença de infiltrado inflamatório é mais discreta, o mesmo ocorrendo com o número de fibroblastos.

\section{○ 15 Dias}

$>$ Grupo I (Controle) - Em alguns casos nas proximidades da abertura do tubo observa-se áreas com numerosos linfócitos e macrófagos ao lado de raros 
fibroblastos (Figura 1B). Nas regiões mais afastadas da abertura do tubo evidencia-se moderado número de fibroblastos, linfócitos e macrófagos.

Em outros espécimes nota-se próximo ao tubo maior número de fibroblastos ao lado de alguns macrófagos e linfócitos.

$>$ Grupo II (Hipoglós $\left.{ }^{\circledR}\right)$ - Em alguns espécimes evidencia-se próximo a abertura do tubo área ocupada por numerosos linfócitos e macrófagos. Nota-se ainda a presença de fibroblastos tanto próximo quanto distante do material (Figura 1E). Nos demais espécimes tecido conjuntivo, exibindo numerosos fibroblastos ao lado de alguns linfócitos, pode ser observado, tanto próximo quanto afastado do material.

\section{○ 21 Dias}

$>$ Grupo I (Controle) - Em todos os espécimes nota-se nas proximidades da abertura do tubo moderado número de linfócitos ao lado de alguns macrófagos. Observam-se ainda fibroblastos, também em número moderado.

Nas áreas mais afastadas da abertura do tubo evidencia-se tecido conjuntivo bem vascularizado com numerosos fibroblastos (Figura 1C) ao lado de raros linfócitos e macrófagos.

Grupo II (Hipoglós®) - Em alguns dos espécimes observa-se junto à abertura do tubo a presença de numerosos macrófagos e linfócitos (Figura 1F) ao lado de alguns fibroblastos. Nestes mesmos animais, nas áreas mais distantes da abertura do tubo, nota-se menor número de macrófagos e linfócitos e maior quantidade de fibroblastos.

Nos demais espécimes, no tecido conjuntivo tanto próximo quanto distante da abertura do tubo evidenciam-se numerosos fibroblastos e raros linfócitos e macrófagos.

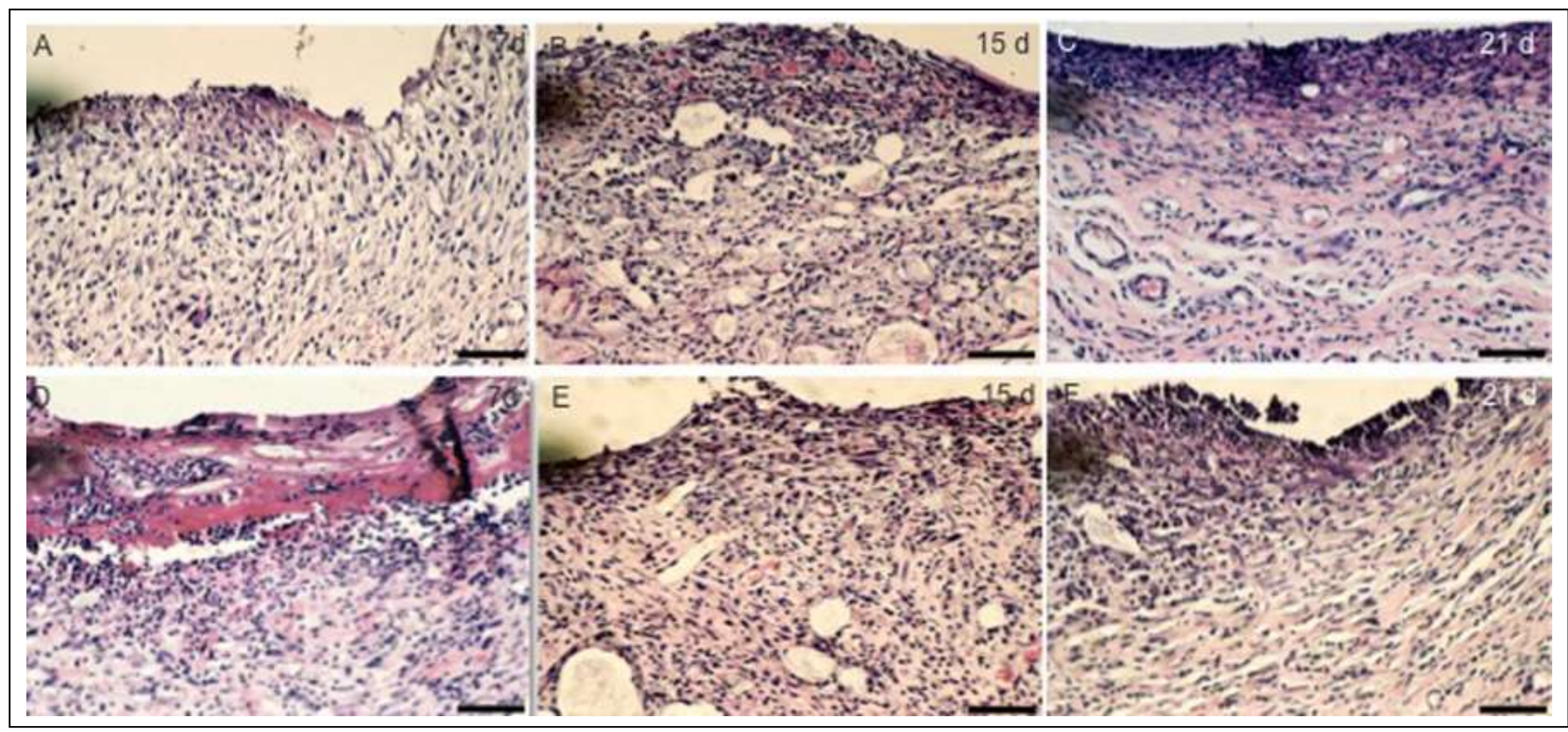

Figura 1: A) Controle -7 dias. Moderado número de fibroblastos, linfócitos e vasos sanguíneos. (HE) Aumento 400X. B) Controle - 15 dias. Elevada quantidade de macrófagos e linfócitos e raros fibroblastos. (HE) Aumento 400X. C) Controle -21 dias. Grande quantidade de fibroblastos e vasos sanguíneos. (HE) Aumento 400X. D) Hipoglós® -7 dias. Elevado número de macrófagos e linfócitos. (HE) Aumento 400X. E) Hipoglós ${ }^{\circledR} 15$ dias. Grande quantidade de macrófagos e linfócitos e poucos fibroblastos. (HE) Aumento 400X. F) Hipoglós ${ }^{\circledR} 21$ dias. Presença de macrófagos e linfócitos ao lado de alguns fibroblastos. (HE) Aumento 400X.

\section{ANÁLISE QUANTITATIVA}

No Grupo Controle (I), observa-se redução estatisticamente significante $(\mathrm{p}<0,05)$ na quantidade de macrófagos entre o $15^{\circ}$ e o $21^{\circ}$ dia. Nota-se ainda no grupo Controle (I) diferença estatisticamente significante $(p<0,01)$, com aumento da quantidade de fibroblastos entre o $15^{\circ}$ e o $21^{\circ}$ dia (Tabela 1$)$.

No Grupo Hipoglós® (II), observa-se redução estatisticamente significante $(\mathrm{p}<0,01)$ na quantidade de macrófagos entre o $7^{\circ}$ e o $15 / 21^{\circ}$ dia. Nota-se ainda no Grupo Hipoglós ${ }^{\circledR}$ (II) diferença estatisticamente significante $(\mathrm{p}<0,01)$, com aumento da quantidade de fibroblastos entre o $7^{\circ}$ e $15^{\circ}$ dia e redução significativa entre o $15^{\circ}$ e o $21^{\circ}$ dia (Tabela 1).

No Grupo Controle (I), não houve diferença estatisticamente significante da quantidade de infiltrado inflamatório no transcorrer dos dias, enquanto o Grupo Hipoglós ${ }^{\circledR}$ (II) apresentou redução estatisticamente significante $(\mathrm{p}<0,01)$ na quantidade de infiltrado inflamatório entre $7 / 15^{\circ}$ e o $21^{\circ}$ dia (Tabela 2 ).
Tabela 1. Média e desvio padrão da somatória dos escores obtidos para cada tipo celular

\begin{tabular}{llllll}
\hline Grupo & Tipo de célula & 7 dias & 15 dias & 21 dias & \\
Controle & Linfócitos & $3,4 \pm 1,1$ & $3 \pm 0,7$ & $4 \pm 0,7$ & NS \\
& Plasmócitos & 0 & 0 & 0 & NS \\
& PMN & 0 & 0 & 0 & NS \\
& Macrófagos & $2,6 \pm 1,3^{\mathrm{ab}}$ & $4,4 \pm 1,5^{\mathrm{a}}$ & $1,8 \pm 0,4^{\mathrm{b}}$ & $\mathrm{p}<0,05$ \\
& Céls. Gigantes & $0,2 \pm 0,4$ & $0,2 \pm 0,4$ & 0 & $\mathrm{NS}$ \\
& Fibroblastos & $7,2 \pm 1,1^{\mathrm{ab}}$ & $5,6 \pm 1,1^{\mathrm{a}}$ & $8,2 \pm 0,8^{\mathrm{b}}$ & $\mathrm{p}<0,01$ \\
Hipoglós® & Linfócitos & $4,2 \pm 2,7$ & $4,2 \pm 1,7$ & $1,2 \pm 1,3$ & $\mathrm{NS}$ \\
& Plasmócitos & 0 & 0 & 0 & $\mathrm{NS}$ \\
& PMN & $1,2 \pm 2,6$ & 0 & 0 & $\mathrm{NS}$ \\
& Macrófagos & $4,8 \pm 1,4^{\mathrm{a}}$ & $1,8 \pm 2,0^{\mathrm{b}}$ & $0^{\mathrm{b}}$ & $\mathrm{p}<0,01$ \\
& Céls. Gigantes & 0 & 0 & 0 & $\mathrm{NS}$ \\
& Fibroblastos & $6,2 \pm 0,8^{\mathrm{a}}$ & $8,6 \pm 1,5^{\mathrm{b}}$ & $6,4 \pm 0,8^{\mathrm{a}}$ & $\mathrm{p}<0,01$ \\
\hline
\end{tabular}

Entre o Grupo Controle (I) e o Grupo Hipoglós $®$ (II) no $21^{\circ}$ dia houve diferença estatisticamente significante na quantidade de infiltrado inflamatório, havendo maior 
quantidade no Grupo Controle (I) quando comparado ao Grupo Hipoglós® (II) (Tabela 2).

Tabela 2. Média e desvio padrão da somatória dos escores correspondente ao infiltrado inflamatório

\begin{tabular}{ll}
\hline Grupos & Média \pm d.p. \\
\hline Controle & $13,4 \pm 3,3$ \\
Hipoglós® & $16,4 \pm 4,4^{\mathrm{A}}$ \\
& $\mathrm{NS}$ \\
\hline
\end{tabular}

\section{DISCUSSÃO}

A metodologia empregada, no tocante à utilização de implantação em subcutâneo de rato para avaliar a biocompatibilidade da substância, foi baseada no trabalho de Torneck $^{10}$ que deu origem a um expressivo número de pesquisas ao longo desse tempo ${ }^{11-13}$. Nesse modelo experimental é possível, guardadas as proporções de resistência do animal e cronologia do processo de reparo tecidual, simular as situações que poderiam ocorrer em seres humanos.

Considerando que o processo inflamatório pode ser desencadeado em consequência de microrganismos, por agressores químicos e físicos, a presença de células inflamatórias (linfócitos, plasmócitos, polimorfonucleares) parece natural quando o tubo de polietileno, mesmo vazio, é implantado no dorso dos animais.

As reações na "luz" do tubo vazio (Grupo I), neste trabalho, foram similares aquelas encontradas por Ozbas et. al. ${ }^{11}$ que demonstraram que os tubos de polietileno provocaram pouca reação em tecido conjuntivo subcutâneo, não havendo diferença estatisticamente significante da quantidade de infiltrado inflamatório no transcorrer dos dias, apesar de existir predominância na quantidade de macrófagos no $15^{\circ}$ dia e de fibroblastos no $21^{\circ}$ dia. Isso se justifica porque em região discreta ou intensamente inflamada ocorre o acúmulo de células provenientes do sistema imunológico, seguido da ingestão e digestão dos antígenos pelos macrófagos e síntese de fibras estruturais para recuperar o tecido pelos fibroblastos.

A utilização do Hipoglós® para análise da reação do tecido conjuntivo subcutâneo em ratos justifica-se pela ausência de trabalhos publicados com esse medicamento em odontologia, podendo ser usado em situações que desencadeiam inflamação. Em contrapartida, estudos em humanos dos componentes que constituem a pomada são frequentes relacionadas à pediatria para o tratamento, principalmente, de dermatite das fraldas ${ }^{14-16}$.

Analisando os dados encontrados nesta pesquisa, observa-se que no grupo Hipoglós ${ }^{\circledR}$ (Grupo II) há predominância de macrófagos no $7^{\circ}$ dia (primeira linha de defesa). Esse dado é justificado por estudo de El Beitune et. $\mathrm{al}^{4}{ }^{4}$, em que há evidências de que os retinóides modulam a resposta de células fagocitárias. Por este mesmo estudo, a grande intensidade de fibroblastos no $15^{\circ}$ dia também parece natural, uma vez que a vitamina $\mathrm{A}$ age na diferenciação e crescimento das células epiteliais.

Assim como o retinol, estudos sobre a vitamina $D^{5}$ e o óxido de zinco ${ }^{14,16}$ comprovam a eficácia desses componentes no reparo tecidual pelo mesmo processo.

Além disso, a presença de PMNs no $7^{\circ}$ dia se justifica porque os neutrófilos são os primeiros a chegar às áreas de inflamação, tendo uma grande capacidade de fagocitose. Estão envolvidos na defesa contra bactérias e fungos.
Dessa forma, as grandes vantagens da utilização desse medicamento são as propriedades anti-inflamatórias que apresentam os metabólitos da vitamina $\mathrm{A}^{4}$ e $\mathrm{D}^{5}$ e o óxido de zinco $^{15,17-18}$ quando aplicados topicamente.

A vitamina A e seus metabólitos naturais têm sido usados para o tratamento tópico e sistêmico da acne crônica, envelhecimento da pele, leucemia promielocítica aguda e Sarcoma de $\operatorname{Kaposi}^{19}$. Além disso, é necessária para o crescimento, diferenciação, manutenção e reprodução do tecido epitelial ${ }^{20}$. Na forma oral ou tópica estimula a diferenciação de células epidermais humanas na placa psorítica $^{21}$.

A vitamina $\mathrm{D}$ e seus metabólitos, assim como o retinol e seus derivados, são efetivos no tratamento da psoríase ${ }^{22}$. Existem relatos ainda do seu papel na proteção contra os raios- $U^{23}$, nas infecções microbianas ${ }^{24}$ e no estresse oxidativo $^{25}$.

Os efeitos do óxido de zinco, por sua vez, são: estímulo da proliferação celular, redução da inflamação, modulação da reação imune e proteção celular. Dessa forma, o óxido de zinco tem sido utilizado em dermatites seborreicas, dermatites de fraldas, acne e "dermatofitoses" comuns (ex: pé de atleta).

\section{CONCLUSÃO}

Assim, em razão dos seus componentes e da semelhança de resposta inflamatória com o grupo controle, a pomada Hipoglós ${ }^{\circledR}$ mostrou-se biocompatível em tecido conjuntivo subcutâneo de ratos e abre a perspectiva para a realização de outras pesquisas.

\section{REFERÊNCIAS}

1. Al Maweri SA, Al Jamei AA, Al Sufvani GA, Tarakji B, Shugaa-Addim B. Oral mucosal lesions in elderly dental patients in Sanaá, Yemen. J Int Soc Prev Community Dent. 2015; 5(Suppl 1):S12-9.

2. Altenburg A, El-Haj N, Zoubolis CC. The treatment of chonic reccurent oral aphthous ulcers. Dtsch Arztbel Int. 2014; 111(40):665-73

3. Lima AS, Grégio AMT, Tanaka O, Machado MAN, França BHS. Tratamento das ulcerações traumáticas bucais causadas por aparelhos ortodônticos. R Dental Press Ortodon Ortop Facial. 2005; 10(5):30-6.

4. El Beitune P, Duarte G, Morais EN, Quintana SM, Vannucchi H. Vitamin A deficiency and clinical associations: A review. Arch Latinoam Nutr. 2003 53(4): 355-63.

5. Pedros MAC, Castro ML. Papel da vitamina D na função neuro-muscular. Arq Bras Endocrinol Metab. 2005; 49(4): 495-502.

6. Lansdown AB, Mirastschijski U, Stubbs N, Scanlon E, Agre MS. Zinc in wound healing: theorical, experimental and clinical aspects. Wound Repair Regen. 2007; 15(1):2-16

7. Molloy D, Goldman M, White RR, Kahani S. Comparative tissue tolerance of a new endodontic sealer. Oral Surgery Oral Medicine Oral Pathology. 1992; 73(4):490-3.

8. Zmener O, Guglielmotti MB, Cabrini RL. Tissue response to na experimental calcium hydroxide-based endodontic sealer: a quantitative study in the subcutaneous connective tissue of the rat. Endod Dental Traumatol. 1990; 6(2): 66-72.

9. Costa CA, Teixeira HM, do Nascimento AB, Hebling J. Biocompatibility of two current adhesive resins. J Endod. 2000; 26(9):512-6. 
10. Torneck CD. Reaction of rat connective tissue to polyethylene tube implants. I. Oral Surg Oral Med Oral Pathol. 1966; 21(3):379-87.

11. Ozbas H, Yaltirik M, Bilgic B, Issever H. Reactions of connective tissue to compomers, composite and amalgam root-end filling materials. Int Endod J. 2003; 36(4):281-7.

12. Sumer M, Muglali M, Bodrumlu E, Guvenc T. Reactions of connective tissue to amalgam, intermediate restorative material, mineral trioxide aggregate, and mineral trioxide aggregate mixed with chlorhexidine. J Endod. 2006; 32(11):1094-6.

13. Gomes-Filho JE, de Faria MD, Bernabé PFE, Nery MJ, Otoboni-Filho JA, Dezan-Júnior E, et al. Mineral Trioxide Aggregate but not Light-cure Mineral Trioxide Aggregate Stimulated Mineralization. J Endod.. 2008; 34(1):62-5.

14. Lansdown AB, Mirastschijski U, Stubbs N, Scanlon E, Agren MS. Zinc in wound heling: theoretical, experimental, and clinical aspects. Wound Repair Regen. 2007; 15 (1):2-16.

15. Davies MW, Dore AJ, Perissinotto KL. Topical vitamin A, or its derivatives, for treating and preventing napkin dermatitis in infants. Cochrane Database Syst Rev. 2005; 19(4):CD004300.

16. Vaz FAC, Celidônio AL, Nunes J, Martins EL, Martins JEC. Clinical trail with two formulations in the treatment of ammoniacal dermatitis of newborns and infants. An Bras Dermatol. 1993; 68(5):301-2.

17. Agren MS. Zinc oxide increases degradation of collagen in necrotic wound tissue. $\mathrm{Br}$ J Dermatol. 1993 Aug;129(2):221.

18. Agren MS, Ostenfeld U, Kallehave F, Gong Y, Raffn K, Crawford ME, et al. A randomized, double-blind, placebo-controlled multicenter trial evaluating topical zinc oxide for acute open wounds following pilonidal disease excision. Wound Repair Regen. 2006; 14 (5):526-35.

19. Reichrath J, Lehmann B, Carlberg C, Varani J, Zouboulis CC. Vitamins as homones. Horm Metab Res. 2007; 39 (2):71-84

20. Savafi K. Serum vitamin A levels in psoriasis: Results from the first national health and nutrition examination survey. Arch Dermatol. 1992; 128(8):1130-1.

21. Orfanos CE, Zouboulis CC, Almond-Roesler B, Geilen CC. Current use and future potential role of retinoids in dermatology. Drugs. 1997; 53(3):358-88.

22. Lehmann B, Querings K, Reichrath J. Vitamin D and skin: new aspects for dermatology. Exp Dermatol 2004; 13(Suppl 4):11-5.

23. De Haes P, Garmyn M, Verstuyf A, De Clercq P, Vandewalle M, Degreef H, et al. 1,25-Dihydroxyvitamin D3 and analogues protect primary human keratinocytes against UVB-induced DNA damage. J Photochem Photobiol B. 2005; 78(2):141-8.

24. Gombard HF, Borregaard N, Koeffler HP. Human cathekicidin antimicrobial peptide (CAMP) gene is a direct target of the vitamin D receptor and is strongly up-regulated in myeloid cells by 1,25-dihydroxyvitamin D3. FASEB J. 2005; 19(9):1067-77.

25. Diker-Cohen T, Koren R, Liberman UA, Ravid A Vitamin D protects keratinocytes from apoptosis induced by osmotic shock, oxidative stress, and tumor necrosis factor. Ann N Y Acad Sci. 2003; 1010:350-3.

\section{CONFLITO DE INTERESSES}

Os autores declaram não haver conflitos de interesse.

\section{AUTOR PARA CORRESPONDÊNCIA}

\section{Maria del Pilar Rodriguez Sánchez}

marypylo@yahoo.com

Submetido em 03/11/2016

Aceito em 01/01/2017 